Петчина Дарья Кирилловна

аспирант кафедры логистики и управления цепями поставок Санкт-Петербургского государственного экономического университета

\section{МЕТОДЫ СНИЖЕНИЯ ЛОГИСТИЧЕСКИХ ЗАТРАТ НА ПРОИЗВОДСТВЕННОМ ПРЕДПРИЯТИИ В СОВРЕМЕННЫХ УСЛОВИЯХ}

Аннотация:

В статье обоснована необходимость внедрения основ логистики на производственном предприятии как главного системного фактора экономичности логистических и на этой основе общих затрат предприятия. Средние логистические затраты на Западе составляют от 10 до 14 \% ВВП, тогда как в России данный показатель достигает значения $20 \%$ ВВП, что свидетельствует о неэффрективном управлении логистическими процессами на российских производственных предприятиях $u$ требует разработки методов снижения логистических затрат предприятий, которые возникают на всех этапах воспроизводственного цикла. В целях сокращения логистических затрат компаний необходимо рассматривать производственное предприятие как единую логистическую систему с координацией и интеграцией всех структур и изучать каждый бизнес-процесс, исключая необязательные процессы, не создающие ценности.

\section{Ключевые слова:}

логистика, логистические затраты, учет затрат, операционный подход, логистика снабжения, логистика производства, логистика распределения, контроллине затрат.
Petchina Daria Kirillovna

PhD student, Logistics and Supply Chain Management Department, Saint Petersburg State University of Economics

\section{METHODS TO REDUCE LOGISTICS COSTS \\ AT MANUFACTURING ENTERPRISE IN THE MODERN CONTEXT}

Summary:

The study substantiates the need to introduce logistics into the enterprise as the main system factor of profitability of logistics and the total costs of the enterprise in this regard. Average logistics costs in the West make from 10 to $14 \%$ of GDP while in the Russian Federation this indicator amounts to $20 \%$ of GDP. This fact confirms poor control of logistics processes at the domestic enterprises and requires the development of meth ods to reduce logistics costs of the enterprises which arise at all reproduction stages. To reduce the logistics costs of the companies, it is necessary to consider the manufacturing enterprise as a unified logistics system coordinating and integrating all structures and study each business process except for the processes which do not create values.

В современном мире возрастает роль логистики, что обусловлено стремлением предприятий на микроуровне и стран на макроуровне к сокращению временных и денежных затрат. Именно логистика является системным фактором экономичности прежде всего логистических и на этой основе общих затрат предприятий. Задача сокращения и контроля затрат представляется для любой компании одной из основных, поскольку от управления затратами предприятия зависит коммерческая политика данной компании, а значит, и конкурентное преимущество и дальнейшее существование фирмы.

Экономика России сегодня столкнулась с рядом внутренних и внешних проблем, таких как экономический кризис, неустойчивость курса валют, ввод двусторонних санкций, напряженная и нестабильная политическая обстановка в мире. В данной ситуации особого внимания требует проблема управления деятельностью российских предприятий в целом, и в особенности проблема управления затратами и процессами предприятия, на что направлен инструментарий логистики.

Средние логистические затраты на Западе составляют от 10 до 14 \% ВВП. Безусловно, затраты на логистику значительно различаются в разных отраслях промышленности и зависят от фракторов, присущих тому или иному виду деятельности. К примеру, затраты на логистику в строительстве значительно выше по сравнению с аналогичными затратами в ювелирном деле и фармацевтике [1]. Однако логистические затраты в РФ составляют около 20 \% ВВП, что указывает на низкую эфффективность управления логистическими процессами в стране. Необходимо разработать методы снижения логистических затрат в структуре общих затрат предприятия и цепей поставок с целью улучшения ситуации, что предоставит возможность инвестировать полученные средства в развитие предприятий, корректировать ценовую политику, повысить уровень обслуживания потребителей. В то же время в исследованиях специалистов в области логистики отмечается неоднозначность трактовки логистических затрат, что влечет за собой несколько подходов к их структуризации. Наиболее известные определения термина «логистические затраты» представлены в таблице 1. 
Таблица 1 - Подходы к определению понятия «логистические затраты»

\begin{tabular}{|l|l|}
\hline \multicolumn{1}{|c|}{ Автор } & \multicolumn{1}{|c|}{ Определение логистических затрат } \\
\hline Н.К. Моисеева & $\begin{array}{l}\text { Логистические затраты представляют собой денежное выражение использованной } \\
\text { рабочей силы, средств и предметов труда, финансовые затраты и различные нега- } \\
\text { тивные последствия форс-мажорных событий, которые обусловлены продвижением } \\
\text { материальных ценностей (сырья, материалов, товаров) на предприятии и между } \\
\text { предприятиями, а также поддержанием запасов [2] }\end{array}$ \\
\hline А.М. Гаджинский & Логистические затраты - затраты на выполнение логистических операций [3] \\
\hline О.А. Сярдова & $\begin{array}{l}\text { Логистические затраты представляют собой затраты материальных, трудовых и ин- } \\
\text { формационных ресурсов, связанных с выполнением логистических операций, обес- } \\
\text { печивающих выполнение заказов потребителей [4] }\end{array}$ \\
\hline В.И. Сергеев & $\begin{array}{l}\text { Общими логистическими затратами называются суммарные затраты, связанные с } \\
\text { комплексом функционального логистического менеджмента и логистическим адми- } \\
\text { нистрированием в логистической системе [5] }\end{array}$ \\
\hline Т.В. Алесинская & $\begin{array}{l}\text { Логистические затраты - это сумма всех затрат, связанныхс выполнением логисти- } \\
\text { ческих операций: размещением заказов на поставку продукции, закупку, складирова- } \\
\text { ние поступающей продукции, внутрипроизводственную транспортировку, промежу- } \\
\text { точное хранение, хранение грузовых потоков, отгрузку, внешнюю транспортировку, а } \\
\text { также затраты на персонал, оборудование, помещение, складские запасы, на пере- } \\
\text { дачу данных о заказах, запасах, поставках [6] }\end{array}$ \\
\hline
\end{tabular}

В результате проведенных исследований под логистическими затратами предлагается рассматривать перенесенную (вмененную) ценность ресурсов на вновь создаваемую ценность (продукт, услугу), обусловленную движением материального и сопутствующих ему потоков (финансового, информационного и пр.) на предприятии и в структуре цепи поставок [7].

Структура затрат, в том числе логистических, и их классификация во многом зависят и определяются спецификой деятельности той или иной компании [8]. Определение состава логистических затрат для каждого предприятия является необходимым мероприятием, что способствует принятию экономически обоснованных, верных управленческих решений. Основной задачей анализа логистических затрат является изыскание фракторов их снижения при сохранении необходимого качества обслуживания, что впоследствии повышает финансовые возможности предприятия. Лишь при правильной организации процессов и эффективном управлении можно минимизировать уровень логистических затрат предприятия.

В отличие от традиционного подхода к учету затрат логистика подразумевает ведение учета затрат на всем пути движения материального потока в рамках операционного подхода, не объединяя затраты в общепринятые группы согласно системе бухгалтерского учета. По данным бухгалтерского учета невозможно осуществлять идентификацию, анализ и контроль логистических затрат. Большинство специалистов в области логистики, как зарубежных, так и российских, выделяют три функциональные области логистики - логистику снабжения (закупочная логистика), логистику производства (производственная логистика) и логистику распределения (сбытовая логистика). Соответственно, объектом анализа логистической деятельности на том или ином этапе воспроизводственного цикла являются разные процессы, операции и функции.

В логистике снабжения к таким процессам и функциям можно отнести расчет потребности в закупаемых ресурсах, поиск и выбор поставщиков, выбор способа внешней транспортировки, организацию складского хозяйства всех закупаемых материальных ресурсов (обычно комплектующих и запчастей), снабжение цехов.

В логистике производства к таким процессам и функциям можно отнести планирование производства, разработку планов-графиков производственных заданий цехам, расчет загрузки производственных мощностей, расчет потребности в материалах и установление нормативов, организацию складского хозяйства материалов незавершенного производства, выбор способа внутрипроизводственной транспортировки.

В логистике распределения к таким процессам и функциям можно отнести планирование процесса реализации готовой продукции, организацию складского хозяйства готовой продукции, выбор каналов распределения готовой продукции, упаковку готовой продукции, отгрузку готовой продукции, выбор способа транспортировки, организацию послепродажного обслуживания потребителей.

Закупочная деятельность - это основная фуннциональная область предприятия, где возникают наибольшие логистические затраты. Это связано непосредственно с организацией самой закупки материальных ресурсов для обеспечения бесперебойного производства и жизнедеятельности предприятия, а также с организацией складского хозяйства закупаемых материалов (поддержанием необходимого уровня запасов). При неэффективной организации процессов закупочной деятельности на предприятии (например, избыточные закупки по неправильному расчету потребности в ресурсах) возникают чрезмерные затраты на закупку, т. е. фрактические потери предприятия, что также влечет за собой иммобилизацию денежных средств в запасах и дополнительные затраты на хранение. 
При неэффективной организации процессов производства продукции также могут возникать излишние логистические затраты, т. е. потери, что часто свидетельствует об износе оборудования, простое производственных мощностей, избыточном количестве запасов незавершенного производства.

При неэфффективной организации процессов сбыта также зачастую возникают излишние логистические затраты, т. е. потери в основном в результате неправильного прогнозирования объема спроса на готовую продукцию.

Так как на всех этапах воспроизводственного цикла осуществляются разные логистические процессы, возникают разные логистические затраты, которые необходимо идентифицировать, анализировать, для сокращения которых необходимо принимать соответствующие меры и в дальнейшем контролировать уровень данных затрат.

В целях сокращения затрат предприятия руководству компании необходимо изучить каждый бизнес-процесс, изменить структуру процессов и задач [9], исключить необязательные, не создающие ценности процессы, рассматривать предприятие как единую логистическую систему с координацией и интеграцией всех отделов, что приводит к синергетическому эффекту.

При управлении логистическими затратами необходимо учитывать их взаимозависимость. Снижение одних затрат приводит к увеличению других (рисунок 1). Интегрированный подход к управлению логистическими процессами требует достижения компромисса, обеспечивающего минимизацию общих затрат при сохранении необходимого уровня логистического обслуживания.

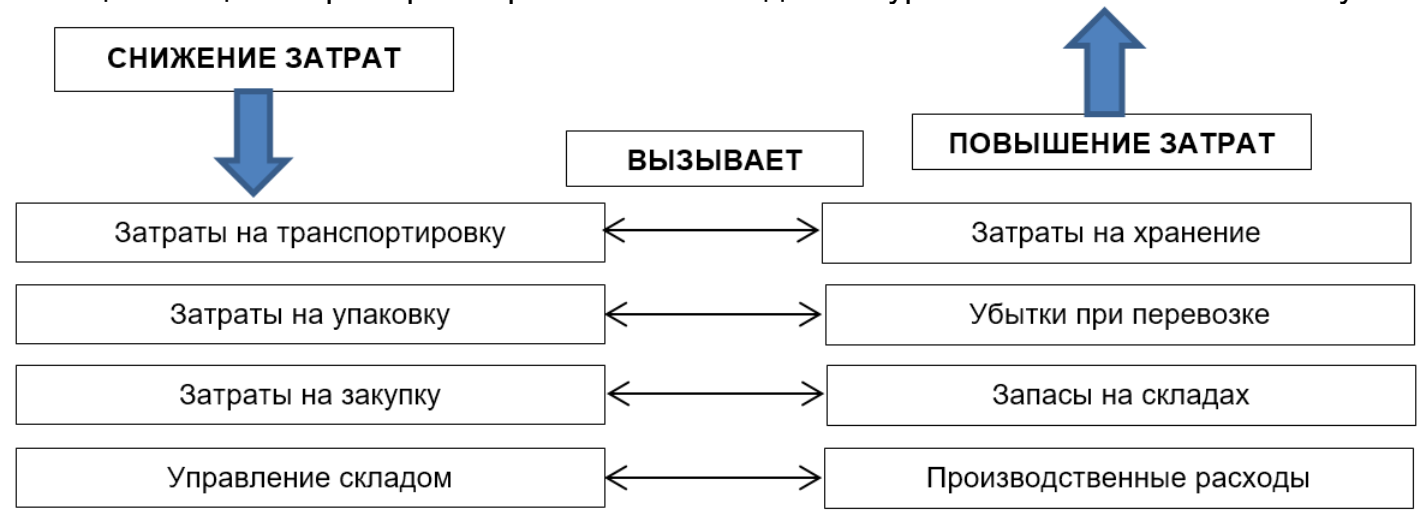

Рисунок 1 - Взаимозависимость логистических затрат [10]

В исследованиях специалистов в области логистики недостаточно раскрыта проблема внедрения и применения конкретных решений по сокращению логистических затрат. Для снижения уровня данного вида затрат производственных предприятий рекомендуется использовать ряд универсальных методов, предложенных автором (таблица 2).

Таблица 2 - Методы снижения логистических затрат производственного предприятия

\begin{tabular}{|c|c|}
\hline $\begin{array}{c}\text { Функциональная } \\
\text { область логистики }\end{array}$ & Методы снижения логистических затрат \\
\hline $\begin{array}{l}\text { Логистика } \\
\text { снабжения }\end{array}$ & $\begin{array}{l}\text { - выбор поставщиков ресурсов с наилучшими предложениями цен и качества про- } \\
\text { дукции; } \\
\text { - координация деятельности предприятия с поставщиками и возможная интеграция; } \\
\text { - поиск более дешевых заменителей ресурсов; } \\
\text { - создание систем регулирования запасов; } \\
\text { - проведение инвентаризации; } \\
\text { - обновление складского оборудования; } \\
\text { - уменьшение ненормативных складских запасов; } \\
\text { - создание единой номенклатуры для учета и поиска ресурсов на складах }\end{array}$ \\
\hline $\begin{array}{l}\text { Логистика } \\
\text { производства }\end{array}$ & $\begin{array}{l}\text { - инвестирование в технологическое и техническое усовершенствование производ- } \\
\text { ства (автоматизация, роботизация, компьютеризированные системы управления); } \\
\text { - совершенствование организации производства и труда; } \\
\text { - аутсорсинг менее производительной деятельности; } \\
\text { - повышение производительности труда и уровня механизации производства; } \\
\text { - повышение технического уровня производства; } \\
\text { - упрощение конструкции изделия }\end{array}$ \\
\hline $\begin{array}{l}\text { Логистика } \\
\text { распределения }\end{array}$ & $\begin{array}{l}\text { - определение точной структуры рынка и прогноз спроса; } \\
\text { - точное исследование каналов распределения; } \\
\text { - повышение точности соблюдения сроков; } \\
\text { - координация деятельности предприятия с дистрибьюторами и возможная инте- } \\
\text { грация; } \\
\text { - аутсорсинг второстепенных процессов }\end{array}$ \\
\hline
\end{tabular}


Главным инструментом сокращения затрат на предприятии является контроллинг. Объект логистического контроллинга - процессы производства как процессы приращения его ценности и накопления затрат, предмет - затраты и ценность производимого продукта [11]. Контроллинг затрат заключается в выявлении факторов, вызывающих отклонения фактических значений затрат от плановых, а также определении места возникновения таких отклонений, нахождении способов их преодоления и поиске путей их минимизации. Осуществление контроллинга затрат требует от предприятия отказа от котлового метода учета затрат и перехода на функциональный/процессный и объектный учет затрат, т. е. по местам их возникновения.

Таким образом, при интегрированном комплексном управлении, внедрении инструментария логистики и контроллинга затрат на предприятии уровень логистических затрат и на этой основе общих затрат предприятия снизится, что приведет к укреплению финансовой устойчивости и усилению конкурентоспособности компании.

\section{Ссылки:}

1. Waters D. Logistics. An Introduction to Supply Chain Management. Houndmills ; N. Y., 2003. 369 p.

2. Моисеева Н.К. Экономические основы логистики : учебник. М., 2008. 528 с. (Высшее образование).

3. Гаджинский А.М. Логистика : учебник. 20-е изд. М., 2012. 484 с.

4. Сярдова О.А. Особенности формирования и учета логистических издержек цепи поставок промышленного предприятия // Вектор науки Тольяттинского государственного университета. Серия: Экономика и управление. 2015. № 1 (20). C. 105-108.

5. Сергеев В.И. Ключевые показатели эффрективности логистики [Электронный ресуpc]. URL: https://iteam.ru/publications/logistics/section_80/article 4351/ (дата обращения: 07.05.2018).

6. Алесинская Т.В. Основы логистики. Общие вопросы логистического управления : учеб. пособие. Таганрог, 2005. 121 с.

7. Козлов В.К., Царева Е.С., Философова Д.К. Экономическое содержание логистического потока: учет и анализ // Логистика и управление цепями поставок. 2017. № 3 (80). С. 57-62.

8. Там же.

9. Миротин Л.Б., Ташбаев Ы.Э., Порошина О.Г. Эффрективная логистика. М., 2003. 160 с.

10. Мясникова Л.А. Логистика : учеб. пособие. СПб., 2013. 135 с.

11. Козлов В.К., Царева Е.С. Производственная логистика (Логистика производства) : учеб. пособие. СПб., 2013. 232 с.

\section{References:}

Alesinskaya, TV 2005, Basics of logistics. General issues of logistics management, manual, Taganrog, 121 p., (in Russian). Gadzhinskiy, AM 2012, Logistics, textbook, 20th ed., Moscow, 484 p., (in Russian).

Kozlov, VK \& Tsareva, ES 2013, Production logistics (manufacturing logistics), manual, St. Petersburg, 232 p., (in Russian). Kozlov, VK, Tsareva, ES \& Filosofova, DK 2017, 'The economic content of the logistics flow: accounting and analysis', Logistika i upravleniye tsepyami postavok, No. 3 (80), pp. 57-62, (in Russian).

Mirotin, LB \& Tashbaev, YE \& Poroshina, OG 2003, Effective logistics, Moscow, 160 p., (in Russian).

Moiseeva, NK 2008, The economic basis of logistics, textbook, Moscow, 528 p., (in Russian).

Myasnikova, LA 2013, Logistics, manual, St. Petersburg, 135 p., (in Russian).

Sergeev, VI 2018, Key indicators of logistics efficiency, viewed 07 May 2018, <https://iteam.ru/publications/logistics/section 80/article 4351/>, (in Russian).

Syardova, OA 2015, 'Features of the development and accounting of logistics costs of the supply chain at an industrial enterprise', Vektor nauki Tol'yattinskogo gosudarstvennogo universiteta. Seriya: Ekonomika i upravleniye, No. 1 (20), pp. 105108, (in Russian)

Waters, D 2003, Logistics. An Introduction to Supply Chain Management, Houndmills, New York, 369 p. 